\title{
Maryse condé e a áfrica no horizonte
}

\author{
Maryse condé and africa in the horizon
}

Maria Letícia Macêdo Bezerra ${ }^{1}$

ORCID: https://orcid.org/0000-0001-5182-530X

\begin{abstract}
Resumo: O presente artigo estuda o deslocamento da escritora guadalupense Maryse Condé à África, tomando como objeto literário duas autobiografias da autora: Le coeur à rire et à pleurer (1999) e La vie sans fards (2012). Consideramos o deslocamento retratado nestas obras para além do físico e espacial, das diásporas negras. Encontra-se, também, um deslocamento afetivo e identitário representado no seu interesse inicial pelo movimento da negritude, na África mítica e no diálogo com o pensamento anticolonialista crescente no século XX. Para o aporte crítico e teórico, apoiamo-nos nos/as autores/as Aimé Césaire, Frantz Fanon, Édouard Glissant, Eurídice Figueiredo, Grada Kilomba, dentre outros/as.
\end{abstract}

Palavras-chave: Deslocamento. Maryse Condé. África. Black diaspora.

Abstract: The present article studies the displacement of the Guadeloupe writer Maryse Condé to Africa, taking as a literary object two autobiographies by the author: Le coeur à rire et à pleurer (1999) and La vie sans fards (2012). We consider the displacement portrayed in these works beyond the physical and spatial ones, of the black diasporas. There is also an affective and identity displacement represented in her initial interest in the negritude movement, in the mythical Africa and in the dialogue with the growing anticolonialist thinking in the $20^{\text {th }}$ century. For the critical and theoretical contribution, we rely on the authors Aimé Césaire, Frantz Fanon, Édouard Glissant, Eurídice Figueiredo, Grada Kilomba, among others.

Keywords: Displacement. Maryse Condé. Africa. Black diaspora.

\section{Introdução}

Toda a obra de Maryse Condé é marcada por uma crise identitária (FIGUEIREDO, 1998) que afeta, de um modo geral, as diásporas negras, em especial a

\footnotetext{
${ }^{1}$ Graduada em Letras Português pela Universidade Federal da Paraíba (UFPB). Bolsista CAPES e mestranda do programa LETRA na Universidade de São Paulo (USP).
} 
antilhana (GLISSANT, 2017). Essa marca aparece na recorrência de um chamado para o exílio e retorno das suas personagens, assim como de si própria em um movimento de fluxo e refluxo. Como diz Nora Cottille-Foley, "essa experiência do exílio e do retorno é encontrada na sua obra, onde a abordagem do espaço ocupa um lugar importante ${ }^{2 "}$ (2006, p. 159). Então, apoiamo-nos, aqui, em duas autobiografias da escritora guadalupense, $L e$ coeur à rire et à pleurer (1999) e La vie sans fards (2012), para trabalhar o movimento de deslocamento de Condé que se revela nos seus relatos de vida, especificamente da sua relação com a África mítica e a negritude.

Nascida em 1937, na cidade de Pointe-à-Pitre, Guadalupe, Condé se mudou ainda adolescente para Paris a fim de finalizar seus estudos e ingressar na educação superior. Essa parte da sua vida, juntamente com sua infância nas Antilhas, é narrada em Le coeur à rire et à pleurer, enquanto La vie sans fards abrange seus anos em Paris, nos países do oeste africano, e em Londres. Ambas as autobiografias mesclam as vozes da Condé que escreve e da Condé passada, viajante, formando uma espécie de testemunho, reflexão.

O diálogo da escritora, vencedora de inúmeros prêmios literários (como o Grand Prix Littéraire de la Femme, 1986, e o "Nobel alternativo", 2018) com os movimentos negristas do século $\mathrm{XX}$ transcende a ficção e se instaura no seu próprio itinerário geográfico. Nestas obras, o espaço se torna portador de significados e os lugares são ressignificados a medida em que são evidenciados em comparação com as suas representações míticas. Em razão disto, reunimos autores/as, pesquisadores/as e críticos/as anticolonialistas, e que estudam as diásporas negras, dos séculos XX e XXI, como Aimé Césaire e Grada Kilomba, para dialogar com essas duas obras literárias de Maryse Condé.

\section{A África no horizonte}

Fixando o seu olhar sobre uma pequena ilha durante os seus passeios de bicicleta, Condé diz que a transformou "em objeto literário, intersecção entre sonho e desejo" (2013, p. 135). Em um outro momento da sua adolescência em Guadalupe, Condé exalta a natureza local, "Eu olhava com muita atenção e tinha a intuição de que tinha nascido,

\footnotetext{
${ }^{2}$ Texto original: "Cette expérimentation avec l'exil et le retour se retrouve dans son œuvre où le traitement de l'espace occupe une place importante".

3 "Je le transfigurais en objet littéraire, intersection du rêve et du désir".
} 
sem saber, em algum canto do paraíso terrestre ${ }^{4 »}$ (2013, p. 122). Uma vez transplantado para o campo literário, e imperando no limiar de sonho, desejo e realização, o espaço geográfico que portará a maior expectativa, e consequentes maiores mudanças, será a África, tendo o mito africano e os estudos etnográficos um papel de grande influência para as epistemologias pós-coloniais, e particularmente o movimento da negritude.

Na chegada de Condé à cidade de Conakry em 1960, por exemplo, ela escreve que "Ela foi a minha verdadeira porta de entrada na África. Aí entendi o sentido da palavra 'subdesenvolvimento'. Fui testemunha da arrogância dos abastados e da miséria dos fracos" ${ }^{5 "}$ (2012, p. 56). A comparação é feita em relação às cidades de Abidjan e Bingerville, na Costa do Marfim, onde ela havia trabalhado como professora por alguns meses. Costa do Marfim tinha uma paisagem idílica e monótona diante da aglomeração de pessoas que encontrou na Guiné, sendo isso o que a escritora esperava encontrar na "verdadeira" África quando partiu de Paris.

Podemos ver que a imagem do continente simbolizada e autenticada pela desigualdade social não circulava apenas no discurso trazido pelos colonizadores como também penetrava a juventude caribenha estudante na Europa. O subdesenvolvimento era a "verdadeira porta de entrada". A África autêntica seria senão a portadora de toda herança colonial, cabendo a/o recém-chegada/o atestar se isso fideliza a sua suposta inferioridade per se ou se provoca o sentimento colateral de atração para uma união comunitária que almeja anular a sua existência dependente da relação de superioridadeinferioridade; opção que atrai Condé, que estava "cada vez menos persuadida de que Paris era a capital do universo" ${ }^{6 \prime}(2013$, p. 111), ou seja, mais interessada em descentralizar o conhecimento.

As versões da África - desde a selvagem até o canto cesariano ao passado de glória - eram o que podia atrair o olhar curioso ou o olhar de quem estava em busca da África “de origem", que não seria encontrada enquanto tudo o que se prometia dela e que se retratava dela não se apresentasse de fato. Perguntada por uma amiga se ela voltaria à Guadalupe, já que, mesmo sem mãe, ela ainda tinha um país, Condé responde que "No momento, algo me mantinha na África. Eu tinha a certeza de que essa terra podia me

\footnotetext{
4 “Je regardais de tous mes yeux et j'avais l'intuition que j’étais née, sans le savoir, dans un coin du paradis terrestre".

5 "Elle a été ma véritable porte d'entrée en Afrique. J'y ai compris le sens du mot 'sous-développement'. J'ai été témoin de l'arrogance des nantis et du dénuement des faibles".

6 "de moins en moins persuadée que Paris est la capitale de l'univers".
} 
oferecer riquezas essenciais $^{7 \% "}(2012$, p. 136). Segundo a autora, a ligação mais forte que lhe restava à Guadalupe era sua mãe. Então, após sua morte, essa ligação não foi sustentada pelo mérito de ser o seu lugar de nascimento e crescimento, em virtude de um sentimento de "ausência de pertencimento".

O exemplo de construção de uma "identidade" que a Guadalupe lhe ofereceu foi através da alienação dos seus pais, que, ao revisitar um episódio da infância, ela descreve da seguinte forma: "Uma pessoa alienada é uma pessoa que busca ser aquilo que ela não pode ser porque não gosta de ser o que ela é (...) Jurei para mim mesma que nunca me tornaria uma alienada ${ }^{8 "}$ (2013, p. 12).

Fugindo da iminência de se valer da assimilação para reprimir e ocultar o que lhe incomoda do seu ser, a África surge no meio do caminho para a sua pergunta do que seria a parte reprimida e oculta da sua história, o que lhe constitui como ser. Outra amiga sugere uma resposta para a sua inquietação: “'É que você está procurando algo totalmente diferente aí (...) Uma terra ocupada que lhe permitiria ser o que você sonha em ser. Nesse ponto, ninguém pode ajudá-la'. Hoje, estou a um passo de achar que ela dizia a verdade ${ }^{9 "}$ (2012, p. 231). A procura por um espaço que lhe permitisse uma liberdade utópica de ser e uma essência isenta de alienação tornava a busca inalcançável e fadada à repetição. Dentre todos os países africanos onde morou, ela percebe que nenhum lhe proporcionou uma conclusiva.

Em um primeiro momento, a experiência na Costa do Marfim, cuja natureza era fatigante, não pareceu ter saciado o desejo por conhecer o retrato "típico" dos países que um dia foram colônias europeias em África. Extenuada pela concentração de riquezas nas mãos de poucos, ela faz o recorte das mazelas que Aimé Césaire enxerga como consequências do "pedantismo cristão": "cristianismo = civilização; paganismo = selvagerismo, das quais só poderiam resultar consequências colonialistas e racistas abomináveis, cujas vítimas deveriam ser os índios, os amarelos, os negros." (CÉSAIRE, 2010, p. 14).

Logo, para Condé, o significado do que a visão eurocêntrica determinava como “subdesenvolvido" seria visto na África, embora as Antilhas não estivessem isentas das

\footnotetext{
7 "Pour l'heure, quelque chose me retenait en Afrique. J'avais la certitude que cette terre pouvait m'offrir des richesses essentielles".

8 “Une personne aliénée est une personne qui cherche à être ce qu'elle ne peut pas être parce qu'elle n'aimes pas être ce qu'elle est. (...) je me fis le serment confus de ne jamais devenir une aliénée".

9 "“C'est que tu y cherches tout autre chose (...) Une terre faire-valoir qui te permettrait d'être ce que tu rêves d'être. Et sur ce plan, personne ne peut t'aider' Je ne suis pas loin de penser aujourd'hui qu'elle disait vrai".
} 
"consequências coloniais e racistas" as quais Césaire se refere. Pensar no continente africano através do olhar europeu não era um absurdo, mas compreensível. A distância (e aproximação) entre África e Antilhas era mediada pela Europa, levando à percepção em via de mão dupla de que os/as antilhanos/as se sentiam superiores as/os africanos/as, como podemos observar nessa fala de Frantz Fanon: “É que o antilhano é mais 'evoluído' do que o negro da África: entenda-se que ele está mais próximo do branco" (2008, p. 40). O autor explica que entre a comunidade negra antilhana e do norte da África circulava uma ideia de distinção. Devido à maior assimilação das Antilhas com a cultura branca europeia, subtendia-se a evolução - o "negro evoluído", que superou as raízes africanas - em detrimento dos povos africanos. Mas se o negro antilhano acredita que é visto e tratado como igual ao homem branco europeu por terem sido criados no meio da "mesma" cultura, desilude-se quando, chegando à Europa, a cor da pele à primeira vista fala mais alto do que qualquer diferença ou assimilação cultural.

Maryse Condé escuta a diferenciação entre antilhanos e africanos na Costa do Marfim através de Mlle Lisette, professora de música do colégio de Bingerville: “Os africanos nos detestam, nós, antilhanos. Eles sentem inveja de nós ${ }^{10 "}$ (2012, p. 41). Embora não opine para sua amiga, ela elabora para o/a leitor/a sobre a visão que as Antilhas destinavam à África: "Para os antilhanos, a África era um contexto misterioso que os amedrontava e que não ousavam decifrar. Eu, ao contrário, sentia atração e me intrigava com esse desconhecido ${ }^{11}$ " $(2012$, p. 43). Esse comentário nos leva a algumas considerações sobre este conjunto de ilhas e a destacar a tentativa da escritora em mergulhar no, para ela até então, desconhecido continente africano estimulada pelos movimentos negristas e pela desilusão com a terra onde nasceu. Desilusão que a levará ao seu "exílio" rememorado em La vie sans fards (2012) e de cujo nascimento de tal desejo é insinuado em Le coeur à rire et à pleurer (2013).

\section{1. O espaço geográfico das Antilhas}

A posição geográfica das Antilhas contribui para o seu isolamento, enquanto a sua dimensão territorial figura empecilhos para que uma cultura tome o tempo e espaço de ser compartilhada e praticada por seus habitantes, fixando-se. Ao contrário das diásporas

\footnotetext{
10 "Les Africains nous détestent, nous les Antillais (...) Ils nous jalousent".

11 “Quant aux Antillais, l'Afrique était un mystérieux background qui leur faisait peur et qu'ils n'osaient pas déchiffrer. Moi, au contraire, cet inconnu à l'entour de moi m'attirait et m'intriguait".
} 
presentes nas Américas do Sul e do Norte, as Pequenas Antilhas não ocupam uma dimensão continental e dividem fronteiras terrestres, logo, não dispondo dos mesmos mecanismos que facilitam a construção e transmissão de tradições. A partir dos conceitos de culturas atávicas e compósitas de Glissant, Eurídice Figueiredo comenta que,

Comparando com os países africanos, que formam comunidades atávicas (com línguas, religiões, valores culturais próprios), podendo resistir ao colonialismo em nome de uma legitimidade ancestral, vê-se que o descendente de escravos na América não tinha nem história nem geografia nas quais pudesse apoiar sua legitimação (1998, p. 98-99).

Após os processos de colonização, do sistema de plantação e sem o mito fundador, criar uma narrativa ausente de base própria dificultava a legitimação da terra. Os anos que levam a se formarem "nações" com culturas e tradições próprias e a incerteza de qual seria essa "propriedade" alimentam o olhar assimilado. A história não se interessou em registrar consideravelmente o que aconteceu nas Antilhas antes da colonização. Na linha do tempo, elas só começaram a existir após terem sido "descobertas” pelos narradores. Os marcos prestigiados e válidos de registro são aqueles que afetaram de alguma forma (positiva ou negativamente) a narrativa da exploração. Os/as migrantes deslocados/as para serem escravizados/as não tiveram a oportunidade de levarem consigo os seus instrumentos, seus alimentos, o seu estilo de vida, nem de manterem contato com quem permaneceu do outro lado. Em território desconhecido, já há muito tempo habitado por nativos e explorado por uma civilização terceira que detinha maior poder de fogo, os novos moradores precisaram entrar em conflito com as culturas dos ancestrais, das outras tribos com as quais dividiam espaço, dos nativos e dos novos habitantes europeus do Novo Mundo.

As Pequenas Antilhas enfrentam, ainda, um outro obstáculo para impedir a assimilação, a saber, a departamentalização francesa. Defendida pelo escritor martinicano Aimé Césaire, que também foi deputado até o ano de 1993, a Martinica e a Guadalupe permanecem departamentos insulares ultramarinos da França desde 1946.

Guadalupe e Martinica, para o bem ou para o mal, entraram no Mercado Comum Europeu e acolheram em seu território milhares de homens e mulheres de todos os tipos de países. (...) Parte deles/as não fala mais a língua crioula, embora permaneça crioulo/a, já que uma simplificação prejudicial, ainda que feita por uma escola de sociologistas, iguala identidade à linguagem ${ }^{12}$ (CONDÉ, 1993a, 130).

12 "Guadeloupe and Martinique, for better or for worse, have entered the European Common Market and welcome on their soil thousands of men and women from all sorts of countries. (...) Part of it no longer 
A diversidade sobre a qual Condé fala - a recepção de outras culturas - será celebrada por Glissant, mas a ligação oficial e legitimada da departamentalização defendida por Césaire foi alvo das críticas a um dos fundadores da negritude pois era vista como um fator propício à assimilação com a cultura francesa, que já vinha em andamento durante o período colonial. A alienação ao passado escravocrata e às suas intercorrências presentes sugere os abismos marcados na história antilhana, em particular, na Guadalupe.

Por um lado, temos a assimilação, responsável por forjar uma ligação benéfica e identificação entre o colonizado e o colonizador, e implantar a falsa ideia de igualdade e reconhecimento de irmandade, que é exemplificada pelo poema Lição, da poeta moçambicana Noémia de Sousa: "Ensinaram-lhe na missão (...): 'Somos todos filhos de Deus; cada Homem é irmão doutro Homem!' / olhou para um Homem e disse 'Irmão...' / Mas o Homem pálido fulminou-o duramente/ com seus olhos cheios de ódio/ e respondeulhe: 'Negro"' (SOUSA, 2016).

Por outro, temos as atrocidades históricas que interromperam a continuidade de culturas e tradições dos/as escravizados/as ao serem transportados para as Américas, transformando as ilhas em lugares onde a memória coletiva de um passado de uma legitimidade conjunta é escassa, como mencionado por Figueiredo. Concomitante a isto, vemos surgirem movimentos, como a negritude, que buscam acabar com o impasse criado para a terra onde os habitantes talvez se sentissem "órfãos" ou adotados pela benevolência do colonizador. Essa ideia aquece Condé ao ouvir falar da negritude em Paris: "minha solidão se aquecia com a ideia de que todos os negros eram parentes ${ }^{13}$ " (2013, p. 147).

Mesmo que essa idealização implicasse um recorte e uma ressignificação da história africana: “consequentemente, da imagem da África, a terra-mãe, foram cuidadosamente erradicadas quaisquer manchas, como a escravidão doméstica, ou

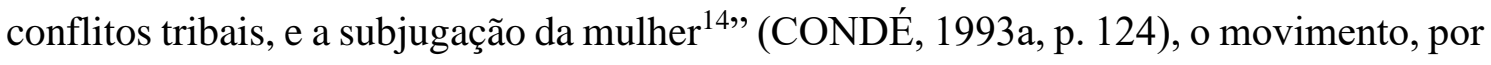
um ponto de vista cultural e ideológico, também significou uma mensagem de reafirmação e conforto, interpretada pela escritora guadalupense, além da reação política que suscitou em prol da libertação do subjugo colonial. Nas palavras de Petrônio Domingues,

speaks the Creole language, although they remain Creoles, since a damaging simplification, albeit made by a school of sociologists, equates identity with language".

13 "ma solitude se réchauffait à l'idée que tous les nègres étaient des parents".

14 "Consequently, from the image of Africa, the motherland, were carefully eradicated any blemishes such as domestic slavery, or tribal warfare, and the subjugation of women”. 
Além da construção da personalidade ou consciência negra, seus adeptos também passaram a protestar contra a ordem colonial e a lutar pela emancipação política dos povos africanos. Assim, depois da segunda Guerra Mundial (1939-1945), o movimento da negritude entrou em uma nova fase, que podemos qualificar de militante (2005, p. 7).

\subsection{A questão da literatura nas Antilhas e a negritude}

A preocupação com a literatura será um denominador comum entre os debates pós-coloniais caribenhos. Ela se insere no cerne formador e fundador das culturas e civilizações uma vez que se torna responsável pelo registro, repasse e inovação de tradições. Enquanto a Europa já possuía uma literatura consolidada e um conjunto de mitos que a "legitimava", iniciou-se uma discussão sobre qual era a literatura caribenha, ou qual ela deveria ser, que pode ser encabeçada pela afirmação "A literatura antilhana não existe ainda. Nós estamos em um estado de pré-literatura: aquele de uma produção escrita sem audiência, desconhecendo a interação autores/leitores na qual se elabora uma literatura ${ }^{15 "}$ (CHAMOISEAU, CONFIANT, BERNABÉ, 1993), do Éloge de la créolité, sinalizando a necessidade de haver um diálogo entre leitor e objeto literário para que exista um estado de literatura. Cada qual procurará fornecer uma visão de projeto para a criação da literatura antilhana:

Como o próprio Glissant coloca, o mar do Caribe, que ele opõe ao Mediterrâneo, não é uma área fechada. Pelo contrário, ele se abre para o mundo e suas variadas influências energéticas. As Antilhas deveriam estar mudando e evoluindo assim como as próprias ilhas. Acima de tudo, criatividade é um processo complexo que não obedece regras. Um/a escritor/a confinado/a a uma pequena e isolada aldeia nas Antilhas é livre para sonhar com uma "Outra Terra" e fazer disso objeto da sua ficção. A imaginação criativa vai além dos limites da realidade e voa para áreas de sua própria escolha. Na verdade, o sonho é um fator que sempre foi negligenciado na literatura antilhana. Ele constitui o objeto de alguns dos mais magníficos escritos do mundo. O seu poder assusta o/a escritor/a antilhano/a? ${ }^{16}$ (CONDÉ, 1993a, p. 130).

\footnotetext{
15 "La littérature antillaise n'existe pas encore. Nous sommes encore dans un état de prélittérature: celui d'une production écrite sans audience chez elle méconnaissant l'interaction auteurs/lecteurs où s'élabore une littérature".

16 "As Glissant himself puts it, the Caribbean Sea, which he opposes to the Mediterranean, is not a closed area. On the contrary, it opens onto the world and its varied energetic influences. West Indians should be as changing and evolving as the islands themselves. Above all, creativity is a complex process which obeys no rules. A writer confined to a small and isolated village of the West Indies is free to dream of "Another Land" and make of it the subject of his/her fiction. Creative imagination goes beyond the limits of reality and soars to areas of its own choice. In fact, dream is a factor which has always been neglected in West Indian literature. It constitutes the object of some of the most magnificent writings of the world. Does its power frighten the West Indian writer?"
} 
Indo em contrapartida ao isolamento territorial das ilhas, Condé concorda com a perspectiva de Glissant sobre o mar ao seu redor garantir a possibilidade de uma abertura para Antilhas. A ausência de fronteiras terrestres que fechem o seu cerco, e a maior distância delas do que vemos no Mar Mediterrâneo, fornece um caminho, oceânico, de passagem para o fluxo de diversidade. Desse modo, o mesmo fator que "isola" o/a escritor/a e dificulta o enraizamento de uma cultura, também permite a "liberdade" dessea escritor/a para ousar "sonhar" e usar da "criatividade". No artigo "Order, Disorder, Freedom, and the West Indian Writer" (1993a), Condé reúne as diferentes “ordens" para a fundação ou proposta de experimentação da literatura caribenha. Dentre elas, cita Suzanne Césaire, com quem Aimé Césaire fundou a revista Tropiques no ano de 1941: “Suzanne Césaire, na revista 'Tropiques', pronunciou o seu famoso comando: 'A poesia martinicana deve ser canibalista ou simplesmente não será'. (...) A partir desse momento, as fundações da ordem foram lançadas ${ }^{17 "}$ (1993a, p. 122).

Em um ritual "canibalístico", a negritude de Césaire toma suas bases a partir do uso do surrealismo à sua maneira, uma utilização da cultura branca ao seu favor na linguagem literária, como Caliban proclama em The tempest, que, agora, terá como usar a língua que lhe foi imposta para aterrorizar e ser compreendido pelos seus opressores. A peça foi, inclusive, reescrita por Césaire, Une Tempête (1969), “Através de sua consciência e de sua revolta, (Caliban) se erige em igual de Próspero, revertendo a relação de senhor-escravo" (FIGUEIREDO, 1998, p. 51). De modo a se desvencilhar dessa relação de dominação, o surrealismo oferecia a liberdade almejada. As influências da França (costumes, filosofia cartesiana etc.), se permanecessem, deveriam fazê-lo apenas na superfície, já que, no fundo, Césaire proclama que é negro. O desejo de não ser reconhecido como negro, de não ter a sua raça como marca, insulta Césaire, que afirma que a negritude nasceu da luta contra a alienação.

\subsection{O deslocamento afetivo e identitário de Maryse Condé à África}

A tomada de conhecimento (e de consciência) dos movimentos que surgiam à época só veio à tona com o deslocamento de Condé pelo continente da Europa (França, em particular) e posta em "prática" no deslocamento ao continente africano. Os percursos que nos fazem compreender como essa ida ao território do colonizador era significativa

17 “Suzanne Césaire, in the journal 'Tropiques', uttered her famous command: 'Martinican poetry shall be cannibalistic or shall not be'. (...) From that time on the foundations of order were laid". 
às diásporas negras são muitos. Antes de tudo, ela evoca a composição desses grupos por uma classe intelectual, que lia e viajava à Europa a fins de estudos, e que, ao se depararem com a própria alienação e entrarem em contato com as "libertadoras" vanguardas europeias, mais um percurso, tornaram a compartilhar entre si um desejo em comum, coletivo, a tomada de consciência negra. O regresso de Maryse Condé à Paris nos anos de 1950 não foi, dessa vez, por motivos de férias em família como era de costume, mas para ingressar no lycée Fénelon.

O desejo de retorno aliado a um não pertencimento ao país de origem são pontos de partida recorrentes nas narrativas de Condé. Seguindo a proposta da negritude e de outros movimentos paralelos, é a África, descoberta na Europa, que aparece como destino ideal:

Um dia, Françoise, uma colega de sala picada pela militância, trouxeme um fino opúsculo cujo título era: Discurso sobre o colonialismo. Eu não conhecia nada do seu autor. No entanto, aquela leitura me perturbou tanto que, no dia seguinte, corri até a livraria Présence Africaine. Comprei tudo o que encontrei de Aimé Césaire. Para dar boa impressão, também comprei os poemas de Léopold Sédar Senghor e de LéonGontran Damas ${ }^{18}$ (2012, p. 28-29).

Maryse Condé embarca em uma busca de si percorrendo caminho semelhante ao qual outros/as escritores/as antilhanos/as seguiram. Não obstante, ainda que não se atenha, em Le Coeur e La vie, aos estereótipos e ideais inalcançáveis, que configuram tanto discursos políticos e literários que escutou nos anos vividos em África e Europa, ela repete o caminho do colonizado através da sua vida, que sente uma pulsão de partida das Antilhas e um olhar ancorado no exterior, seja na filosofia europeia (assimilação) ou no culto à África mediado pela vanguarda europeia (desvio).

Para Glissant, agir dessa maneira apresenta uma ameaça de desaparecimento das culturas antilhanas e um desvio direcionado à assimilação (1981; 2017), “Glissant, por conseguinte, recomenda 'voltar ao local de origem'. O desvio só é um truque lucrativo se o retorno for proveitoso ${ }^{19}$ " (COTTILLE-FOLEY, 2006, p. 159). As tentativas de um

\footnotetext{
18 "Un jour, Françoise, une camarade de classe, qui se piquait de militantisme, m'apporta un mince opuscule qui portait en titre : Discours sur le colonialisme. Je ne savais rien de son auteur. Pourtant, sa lecture me bouleversa tellement que le lendemain, je me précipitai à la librairie Présence Africaine. J'achetai tout ce que je trouvai d'Aimé Césaire. Pour faire bonne mesure j'achetai aussi les poèmes de Léopold Sédar Senghor et de Léon-Gontran Damas".

${ }^{19}$ « Glissant recommande par conséquent de "revenir au lieu. Le détour n'est ruse profitable que si le Retour le fécond".
} 
regresso "bem-sucedido", no sentido de se encontrar, se identificar nessa ancestralidade, se por um lado são falhas, por outro, evidenciam um desejo presente.

Em Condé, ele nasce de um sentimento compreensível concomitante ao trauma da assimilação que ocorreu durante a sua infância. O desprendimento das suas "origens materiais" lhe impulsiona a desviar-se de uma busca "interna", que voltaria o seu olhar para as próprias ilhas e não para outros continentes. Observando o comportamento das turistas estadunidenses que conheceu durante uma excursão ao Benin, ela diz que "Eu não podia me comunicar com elas. Para mim, a África não representava nem um desterro nem um parêntese na minha existência. Era o espaço dentro do qual eu me debatia há $\operatorname{anos}^{20 "}$ (CONDÉ, 2012, p. 201).

Enquanto a África era um destino turístico para elas, para Condé representava um enigma que sempre lhe trouxe inquietação. As Antilhas perdem o seu significado para a escritora ao ser reduzida a um símbolo de alienação, e, assim, é para o externo que o seu interesse se desloca. O cerco da pequena burguesia, que não permitia o fluxo de tradições e inovações internas, desaparece em outras terras e o debruço sobre os países africanos que vinham acordando uma consciência anticolonial e antirracista se torna mais atrativo do que as minúcias do estado de "pré-literatura".

Estando no momento na Costa do Marfim, Condé recebe a notícia do falecimento do seu pai e descreve o que isso representou: "Eu não era apenas uma órfã. Era uma apátrida, sem-teto, sem terra natal, sem pertencer a lugar nenhum. Ao mesmo tempo, porém, tinha a sensação de uma liberdade que não era de todo ruim: a de estar protegida de todos os julgamentos de agora em diante ${ }^{21 "}$ (2012, p. 49). Originar-se e pertencer recebem significado mais abstrato e flutuante, e, por enquanto, não há lugar que se insira nessa função, caminhando em direção a uma liberação de definições e essencialização. $O$ não abandono da sua atração pela África, mesmo já consciente da sua imprecisão, revela a força motora que isso significou para as construções identitárias das diásporas negras.

Antes de performar o retorno benéfico recomendado por Glissant, o desvio apresentou-se necessário para retribuir o sentimento de "apátrida" com uma "garantia" de liberdade, como bem comenta Mbembe: "Mas para que essa experiência do percurso e do êxodo tenha sentido, é preciso que ela faça parte essencial na África. É preciso que ela

\footnotetext{
20 "Je ne pouvais communier avec eux. Pour moi, l'Afrique ne représentait ni un dépaysement ni une parenthèse dans mon existence. C'était le périmètre à l'intérieur duquel je me débattais depuis des années". 21 “Je n'étais pas seulement orpheline ; j'étais apatride, une SDF sans terre d'origine, ni lieu d'appartenance. En même temps, cependant, j'éprouvai une impression de libération qui n'était pas entièrement désagréable : celle d'être désormais à l'abri de tous jugements".
} 
nos leve de volta à África, ou ao menos que ela faça um desvio pela África ${ }^{22 "}$ (2015, p. 208).

A relação da escritora com o continente africano se inicia muito antes de ela chegar até ele. Ela será teoricamente aprofundada a partir do seu círculo de amizade e debates em Paris e das demandas que os estudos na métropole lhe farão. Alguns fatores impulsionam e fortalecem esse laço ancestral que é ressignificado por ela.

Temos a presença do racismo, que, anteriormente, não se manifestava para ela com a mesma veemência sentida no território predominado pelo colonizador. A discriminação e a redução de Condé à figura estereotipada da "negra" será um choque ao mesmo tempo que uma revelação, não instantânea, para ela de que a raça negra, ainda mais atribuída à tudo que é dado como "ruim", é um produto, uma invenção do mundo branco. E isso pode ser estampado, por exemplo, na medida em que a sua cor e fisionomia provocam espanto, curiosidade, e aversão nas pessoas ao redor, algo que, na Guadalupe, onde a maioria da população é negra, era menos provável de acontecer.

Um desses primeiros episódios é constatado pela escritora, em Le coeur à rire et à pleurer, já adulta, descrevendo o evento de quando era criança em uma das férias com a sua família em Paris:

um emaranhado de metrô e ônibus onde as pessoas comentavam sem me perturbar: - Ela é uma gracinha, a negrinha! Não era a palavra 'negra' que me irritava. Naquele tempo, era bem comum. O problema era o tom. A surpresa. Eu era uma surpresa. A exceção de uma raça que os brancos insistiam em acreditar ser repulsiva e bárbara ${ }^{23}$ (CONDÉ, 2013, p. 112).

A provocação que nós vimos acima, compartilhada por Maryse Condé, também vemos abaixo: uma experiência semelhante de primeiro contato com essa realidade, que é relatada pela escritora estadunidense Audre Lorde. Ela, aos três anos de idade, acompanhada pela sua mãe no metrô de Nova York, sente o olhar obcecado de uma mulher sentada ao seu lado:

A sua boca se contorce enquanto ela me encara e depois o seu olhar abaixa, arrastando o meu com ele. (...) Ela sacode o seu casaco para

\footnotetext{
22 "Mais pour que cette expérience du parcours et de l'exode ait un sens, il faut qu'elle fasse une part essentielle à l'Afrique. Il faut qu'elle nous ramène à l'Afrique, ou du moins qu'elle fasse un détour par l'Afrique".

23 "un enchevêtrement de métro et d'autobus où les gens commentaient sans gêner sur ma personne: - Elle est mignonne, la petite négresse! Ce n'était pas le mot 'négresse' qui me brûlait. En ce temps-là, il était usuel. C'était le ton. Surprise. J'étais une surprise. L'exception d'une race que les Blancs s'obstinaient à croire repoussante et barbare".
} 
perto dela. Eu observo. Não enxergo qualquer coisa de terrível que ela esteja vendo no assento entre nós - provavelmente uma barata. Mas ela comunicou o seu horror para mim. Deve ser algo muito ruim pelo jeito que ela está olhando. (...) E de repente eu percebo que não há nada se rastejando no assento entre nós; sou eu que ela não quer que o seu casaco toque $^{24}$ (LORDE, 2007, p. 157)

Dessa vez, o olhar não é de surpresa pelo exótico, mas de asco acompanhado pelo medo. Embora o primeiro sirva condescendência no tom, ele prerroga a arrogância da crença numa superioridade racial, que é representada pelo horror, quando Lorde se transforma em uma "barata" aos olhos da mulher branca. Em termos psicanalíticos, com abordagem nos estudos fanonianos, Grada Kilomba nos diz que "isso permite que os sentimentos positivos em relação a si mesma/o permaneçam intactos - branquitude como a parte 'boa' do ego - enquanto as manifestações da parte 'má' são projetadas para o exterior e vistas como objetos externos e "ruins"” (2019, p. 25). O "outro" é destituído do direito de fala uma vez que representa a "outroridade" do sujeito branco, e se torna apenas o "animal”, a "surpresa". Mas, como essa projeção ocorre de forma unilateral, um impondo-se sobre o outro, e instaurando-se como uma verdade universal, o sujeito negro que recebe uma educação aos moldes da tradição europeia não se verá, a princípio, como excluído dessa comunidade, como sendo esse "outro" que personifica os "objetos ruins".

Segundo Cheikh Anta Diop, “esse clima de alienação finalmente afetou profundamente a personalidade do Negro, especialmente o Preto educado que teve a oportunidade de tornar-se consciente da opinião pública mundial sobre ele e seu povo" (1974, p. 62). A alienação será responsável por construir no negro um imaginário de desconhecimento dessa "opinião pública mundial" sob as bases da assimilação. As origens da mesma educação que fundamenta esse processo serão também aquelas que oferecerão ferramentas para o "contraponto". Para desconstruir essa ilusão de pertencimento e igualdade, que, mais do que um delírio coletivo e espontâneo, é um projeto cuidadosamente pensado e sistematizado ao longo de anos - "Fanon se colocava contra todo o essencialismo e demonstrava que os 'negros' só existiam de tal forma na

\footnotetext{
24 "Her mouth twitches as she stares and then her gaze drops down, pulling mine with it. (...) She jerks her coat closer to her. I look. I do not see whatever terrible thing she is seeing on the seat between us - probably a roach. But she has communicated her horror to me. It must be something very bad from the way she's looking. (...) And suddenly I realize there is nothing crawling up the seat between us; it is me she doesn't want her coat to touch".
} 
percepção dos europeus ${ }^{25}$ " (CONDÉ, 2012, p. 112) -, será necessário, antes, que o sujeito seja confrontado pelo discurso colonial que legitima a estrutura racista.

A desinformação sobre o passado colonial de escravização e o lugar ocupado em uma pequena burguesia negra na cidade de Pointe-à-Pitre, que, naquele espaço, distancia seus integrantes da interação direta com a comunidade europeia, contribuem para a incompreensão histórica de um acontecimento na infância de Maryse Condé. Durante os passeios por uma praça local com os seus pais, a escritora criança conheceu uma garota branca e loira da mesma faixa etária. As duas logo iniciaram uma "amizade", uma relação na qual Anne-Marie comandava e impunha suas ordens sádicas para Condé, que as seguia: "Eu fui o cavalo. Ela montou nas minhas costas e chutou minhas costelas. Eu era a criada e ela me bateu ${ }^{26}$ ". Cansada dessas brincadeiras, a escritora indaga por que AnneMarie lhe batia, ao que a menina responde: “-Tenho que te bater, porque você é uma negra" (2013, p. 44).

As brincadeiras exigiam a submissão de Condé aos caprichos de Anne-Marie, remetendo-nos ao retrato Babá brincando com criança em Petrópolis (1889) de Jorge Henrique Papf, no qual vemos uma babá negra montada por uma criança branca. Sobre essa imagem, Aline Bocchi reflete "No silêncio desse corpo arquejado e aparentemente embrutecido pela aspereza da cena, o olhar estabelece uma abertura ao processo de significação, permitindo outros sentidos para a mulher negra" (2019, p. 143). Os castigos se repetiam com a total entrega de Condé, que não compreendeu por que ela "deveria apanhar" por ser negra. Não conseguiu pensar em motivo algum que justificasse aquela fala e não teve lembrança de tê-la escutado anteriormente, o que, apesar da sua pouca idade, seria mais frequente caso circulasse em outro ambiente, como aconteceu quando esteve em Paris. Parecia-lhe mesmo esquisito o tal posicionamento, então quis saber dos pais o que aquilo significava.

Uma informação importante para esse cenário é que a sua amiga falava crioulo, enquanto Condé falava francês. Ainda que pertencesse a um círculo social com certo "privilégio" de status dentro da sua comunidade, o corpo negro, "carregado de memória e história" (BOCCHI, 2019), é a única informação que importa para que se construa sobre

\footnotetext{
25 "Fanon se posait contre tout essentialisme et démontrait que les 'Noirs' n'existaient en tant que tels que dans la perception des Européens".

26 "Je fus le cheval. Elle monta sur mon dos et elle me bourra les côtes de coups de pied. Je fus la bonne et elle me souffleta. (...) - Je dois te donner des coups parce que tu es une négresse".
} 
ele uma narrativa de abjeto, de inferior, de dominado, por isso é necessário, para AnneMarie, representando aqui um discurso colonial, que se bata nele.

Mas Condé não se convence com a justificativa inusitada e ela, em uma voz que se confunde também com a sua adulta e mais experiente, percebe que algo muito além da sua compreensão, naquele instante, jazia sob a afirmação da sua "amiga" branca: "Sentia que a resposta daria a chave do edifício do meu mundo, muitas vezes misterioso ${ }^{27}$ " $(2013$, p. 45). Certamente, o seu estranhamento diante do tratamento sádico dado a ela é ainda mais significativo quando observamos a estrutura social de Guadalupe na época do ocorrido e a estrutura familiar da escritora. Segundo ela, "Naquele tempo, em Guadalupe, a gente não se misturava. Negros andavam com negros. Mulatos com mulatos. Os blancspays ficavam na sua esfera e o bom Deus abençoava tudo do seu céu ${ }^{28 ”}$ (2013, p. 56).

O/a alienado/a estaria sempre à espera de alcançar o valor universal branco - e com isso o estilo de vida que obrigatoriamente é aspirado por todo/as - preestabelecido através da negação do seu próprio arredor. A existência de interesse por parte da Europa na manutenção da sua dominação sobre os países colonizados era irrefutável. Dentre os mecanismos de dominação, encontra-se a francofonia, que é vista tanto por Maryse quanto por Césaire (1955), como uma questão não apenas cultural, mas também política. Seguindo essa visão, entende-se que os países africanos que já conquistaram sua independência da França ainda se veem dependentes linguisticamente no que concerne à sua produção artística cultural. A França consegue reforçar a superioridade linguística, mantendo uma espécie de relação entre colônia e metrópole (CONDÉ, 1993b).

O encontro entre Condé e Anne-Marie, visto anteriormente, desenterra um "segredo" que a família da primeira evitava a sua menção. Após insistir por uma resposta para os seus pais, o máximo que obtém são uma repreensão, "você é inteligente demais para perguntar tais coisas", e uma pergunta retórica, se ela já viu alguém batendo na mãe e no pai por serem negros. Não satisfeita com a vagueza da réplica, ela conclui que:

$\mathrm{Eu}$ sentia que havia um segredo escondido no fundo do meu passado. Segredo doloroso, vergonhoso, que seria impróprio e, talvez, perigoso tentar conhecer. Era melhor enterrá-lo nas profundezas da minha memória, como meu pai, minha mãe e todas as pessoas com quem convivíamos pareciam ter feito ${ }^{29}(2013$, p. 46$)$.

\footnotetext{
27 “Je sentais que la réponse fournirait la clé à l'édifice souvent mystérieux de mon monde".

28 "En ce temps-là, en Guadeloupe, on ne se mélangeait pas. Les nègres marchaient avec les nègres. Les mulâtres avec les mulâtres. Les blancs-pays restaient dans leur sphère et le Bon Dieu était content dans son ciel".

29 “Je devinais qu'un secret était caché au fond de mon passé, secret douloureux, secret honteux dont il aurait été inconvenant et peut-être dangereux de forcer la connaissance. Il valait mieux l'enfouir au fin fond
} 
Restando quase ninguém que eles poderiam frequentar, a diversidade e troca de conhecimentos minguavam na casa de Condé. À princípio, como ela mesma sugere, a estratégia de ignorar o assunto adotada pelos pais pareceria valer a pena. Seria uma forma de proteção contra o que haveria além da sua bolha hermética. Diante da evidência de um perigo eminente, ela sente medo de evocar essa memória dolorosa.

Mas a obstinação por esse mistério não cessará e, ao longo do tempo, ela aliou-se à crescente repulsa pela visão burguesa com a qual os seus pais concebiam o mundo. Qualquer relação com a ancestralidade africana renegada (por vergonha) ou desconhecida (por alienação) era um sinal de efeito do capitalismo, era aquilo que ele buscava a fim de assimilar o colonizado e inseri-lo no seu mercado de consumo e na força de produção (por exploração).

Por essa perspectiva, haveria um rompimento com a descendência entre o negro escravizado e traficado da África e os seus descendentes nas diásporas negras das Antilhas "francesas". Essa linha havia sido cortada pelos antilhanos, que, uma vez "livres" e "adotados" pela "pátria-mãe" europeia, tomavam preferência por carregar a marca da "filosofia cartesiana" e da "retórica francesa" em detrimento da relação com o sujeito escravizado e destituído de voz e lugar. Em uma inversão na classificação de países (natal, como em "Diário de um retorno ao país natal" - de adoção), Condé adjetiva as viagens da família à França: "primeira escala no caminho de volta ao país adotivo” (2013, p. 6).

Na Guiné, Condé adquire o passaporte local e aquele momento significa mais do que um ato político e social, representa, como ela diz, uma reapropriação. Serve como uma legitimação da busca pelas "questões de identidade": "Essa reapropriação material da África me provava que indo mais longe que o primeiro da fila da Negritude, meu mestre, eu começava a me assumir" (2012, p. 58). Condé se coloca como discípula de Césaire, e o processo de procura aponta para um propósito maior do que responder as perguntas fundamentais. É nesse itinerário que se encontra a África. A escritora se "assume" seguindo os passos do seu mestre que a leva a materialização da negritude.

A reapropriação permeia a obtenção do passaporte de um país africano, uma espécie de "pertencimento" simbolizado e legitimado, apropriar-se de algo que um dia já foi seu por direito e roubado, enquanto a apropriação permeia a relação imbricada entre

de ma mémoire comme mon père et ma mère, comme tous les gens que nous fréquentions, semblaient l'avoir fait". 
as vanguardas europeias e as culturas africanas, escamotear de quem lhe usurpou. Souleymane Diagne aduz que "o conceito de apropriação está aqui para ser entendido como a combinação intrincada da 'distância de', e 'intimidade com', da linguagem que constitui a experiência poética conhecida como Negritude" (2001, p. 21, grifo do autor).

Mas para estabelecer e encontrar a identidade que tanto se busca é preciso assumir que a sua negritude e que as diásporas negras possuem uma história, não são uma raça que "nasceu ontem", depois do homem branco. As civilizações africanas fizeram contribuições à história das civilizações. Césaire clama que seja reconhecido o fato de a herança delas não permanecer no passado, pois ainda tem valores a contribuir.

Foi a partir desse sentimento de solidariedade que surgiu a ideia de uma civilização negra espalhada pelo mundo, e unida por um ancestral em comum. A África é território onde o renascimento seria possível. Renascer sem as mágoas do passado, sem a marca da escravidão, de volta ao berço materno. O desvio que se parecia mais com um retorno intercambiado pela literatura de Césaire: "Acreditava que se eu chegasse no continente cantado pelo meu poeta favorito, poderia renascer. Voltar a ser virgem. Eu teria todas as esperanças novamente. A lembrança má de quem tinha me feito tanto mal não pairaria mais" (CONDÉ, 2012, p. 31). Permitir-se a esperança, apreciar a espera, a reconstrução de uma nova Condé. O continente africano ajudaria a afastar até mesmo a lembrança de uma desilusão amorosa, “celui qui m'avait fait tant de mal”, contanto que ela proclamasse a voz do seu "poeta favorito" ao adentrar seu "novo" lar.

\section{Considerações finais}

Escavando a memória e a história em busca de algo anterior que lhes faça jus e lhes exorcisse do trauma da escravidão, a negritude encontrará a África como a representante ideal para todo/as o/as negro/as injustiçado/as porque teria sido de lá que todo/as vieram. Então, não somente haverá uma preocupação em revitalizar a "moral” do negro através da união e da coletividade, mas em minar a já decadente cultura e sociedade europeia, responsável por essas fantasias.

No meio disso, Condé também se "encontrará", na sua escrita (embora reveja alguns posicionamentos como veremos no próximo capítulo), e dirá que "desde que descobri Aimé Césaire e os poetas da Negritude, só dava pouco crédito às produções culturais europeias” (2012, p. 189). O impacto com o qual ela descreve revela a força 
motora que o movimento, especialmente quando contraposto às "produções culturais europeias", operou sobre questões pós-coloniais.

Ao final de Le coeur à rire et à pleurer e La vie sans fards, sentimos o todo como uma espécie de preparação, de rota navegada até o início do processo de escrita, acumulando vivências e mudanças de posicionamentos. Por quê, como e quando as ideias surgiram, conjunto que tomará tempo a ser percebido como tal era, o que significava e que será comparado, em um momento no jardim, com uma experiência mística, ainda sem forma de linguagem específica: “Aquilo permaneceu uma experiência inexplicável e quase mística" (2012, p. 212). Detalhes que parecem pequenos, como fragmentos de diálogos, e outros nem tanto, como crimes do governo contra a população, são transportados para narrativas ficcionais.

Segundo Bonnie Thomas, "As obras de Condé consistentemente demonstram como o pessoal se torna uma poderosa expressão do político" (2013, p. 3). Antes de eventos pontuais, cuja inspiração direta é admitida acima por Condé em La vie sans fards, os contornos que as histórias recebem dialogam com a proximidade entre a autora e o sentimento de exílio, que resultará no nomadismo da sua vida, também retratado na sua obra. A escritora dialoga com esses aspectos em consonância de maneira a se inserir em um coletivo, e uma geração, que se vê desviada e ansiosa por uma saída dentre tantas vias apresentadas e articuladamente impostas.

A escritora compartilha da opinião de que a negritude deveria ser vista a partir de um ponto de vista histórico - o próprio Césaire (1955) reconhece que é conhecido como "profeta do regresso" por voltar o seu olhar ao passado pré-europeu, mas se justifica ao falar da importância de se conhecer a história para compreender o pensamento atual. Apesar da distância cronológica entre Condé e a sua ancestralidade, medir e monitorar a influência que tais invasões e "intercâmbios" culturais sucedeu é um trabalho frágil já que os objetos manuseados são relações humanas e o espaço é geopolítico e temporal. Ao longo das narrativas, ela se distanciará ideologicamente da África de Césaire, revendo e ressignificando o seu "desvio".

\section{Referências}

BERnABÉ, J. : CHAMOISEAU, P. ; CONFIANT, R. Éloge de la Créolité. Paris : Gallimard, 1993.

CÉSAIRE, A. Discurso sobre o colonialismo. Letras contemporâneas, 2010.

CONDÉ, M. La vie sans fards. Paris : Éditions Jean-Claude Lattès, 2012. 
CONDÉ, M. Le cœur à rire et à pleurer. Paris: Les Éditions Didier, 2013.

CONDÉ, M. Order, Disorder, Freedom, and the West Indian Writer. Yale University Press, 1993a.

CONDÉ, M. ; PFAFF, F. Entretiens avec Maryse Condé. Condé-sur-noireau : Karthala, 1993b.

COTTILlE-FOlEY, N. Maryse Condé Entre Pulsion de Départ et Pulsion de Retour: Une Réappropriation de L'Espace Antillais. Journal of Caribbean Literatures, Vol. 4, No. 2, Migrations \& Metissages, 2006.

DIAGNE, S. B. Africanity as an open question. In: DIAGNE, S; MAMA, A.; MELBER, H.; NYAMNJOH, F. B. Identity and Beyond: Rethinking Africanity. Uppsala: Nordiska Afrikainstitutet, 2001.

DIOP, C. A. A origem africana da civilização: mito ou realidade. Lawrence Hill \& CO, 1974.

DOMINGUES, P. Movimento da negritude: uma breve reconstrução histórica. Mediações - Revista de Ciências Sociais, Londrina, v. 10, n.1, p. 25-40, jan.-jun. 2005. FANON, F. Pele negra, máscaras brancas. Salvador: EDUFBA, 2008.

FIGUEIREDO, E. Construção de identidades pós-coloniais na literatura antilhana. Niterói: EDUFF, 1998.

GLISSANT, É. Le discours Antillais. França: Folio Essais, 2017.

KILOMBA, G. Memórias da plantação. Rio de Janeiro: Cobogó, 2019.

LORDE, A. Sister outsider. Berkeley: Crossing Press, 2007.

MBEMBE, A. Critique de la raison nègre. Paris : La découverte, 2015.

SOUSA, N. Sangue Negro. São Paulo: Editora Kapulana, 2016.

THOMAS, B. The Cook and the Writer: Maryse Condé's Journey of Self-Discovery. PORTAL, vol. 10, no. 2, Julho 2013.

Artigo recebido em: 20.05.2021

Artigo aceito para publicar em: 30.06.2021 